\title{
Behavioural effects of phenobarbitone and phenytoin in small children
}

\author{
C J BACON, J D CRANAGE, A M HIERONS, M D RAWLINS, AND J K G WEBB \\ Department of Child Health and Department of Pharmacological Sciences, Newcastle University, \\ Nericastle upon Tyne
}

SUMMARY Mothers of 56 children under 2 years old taking phenobarbitone and mothers of 55 children taking phenytoin recorded on questionnaires changes they had noted in the children's behaviour 3 and 9 weeks after starting the drug. Severe behavioural disturbance was noted by many, but the pattern and incidence was similar to that recorded by the mothers of 50 children starting a placebo, and we attribute it to the effect of a recent hospital admission. There was a small improvement in the behaviour of $20 \%$ of children who had been taking phenobarbitone for a year when they stopped it, but in this age group the disturbance caused by phenobarbitone did not appear to have been great.

It is generally agreed that phenobarbitone may disturb the behaviour of small children, ${ }^{1-4}$ but there are few studies of the exact frequency and character of the disturbance. Estimates of frequency vary widely: some authors consider that it mainly affects children with pre-existing behavioural or neurological disturbances, while others regard it as so common as to contraindicate the drug in children. ${ }^{5-6}$ The only placebo-controlled study yet reported is that of Camfield et al. ${ }^{7}$ who found that $43 \%$ of toddlers taking phenobarbitone exhibited disturbed bohaviour compared with $20 \%$ taking placebo. The adverse symptoms most often described are excessive activity, awkwardness, and sleep disorders. Camfield et al. found a distinctive disturbance of sleep in which the child awoke and became fully alert for a period in the middle of the night.

Behavioural disturbance is listed too as an adverse effect of phenytoin in children, ${ }^{8}$ but its frequency and character do not seem to have been studied.

We have therefore attempted to delineate the behavioural effects of phenobarbitone and phenytoin in children under age 2 years in the course of a study on the prophylaxis of febrile convulsions recently carried out in Newcastle and Gateshead. ${ }^{9}$

\section{Method}

Any child admitted to hospital with a first febrile convulsion before age 2 years was, if the parents agreed, randomly allocated to a year's treatment with phenobarbitone, phenytoin, or placebo, with stratification for age (below 14 months and 14-23 months), gender, and severity of initial convulsion. The phenobarbitone and placebo were prepared as powders identical in colour and taste, and the phenytoin as a suspension (Epanutin, Parke Davis), initial dosages being $5 \mathrm{mg} / \mathrm{kg}$ a day for phenobarbio tone and $10 \mathrm{mg} / \mathrm{kg}$ a day for phenytoin. Therapy was begun during hospital admission, which laste $\overline{6}$ between 1 and 3 days, and salivary concentration were checked in the clinic after 3 and 9 weeks and then every 3 months, with adjustments of dosage so as to achieve salivary levels of 8-16 mg/l (34-69 $\mu \mathrm{mol} / \mathrm{l})$ for phenobarbitone and 1.0-2.0 $\mathrm{mg} / 1$ (4-8 $\mu \mathrm{mol} / \mathrm{l})$ for phenytoin, which are about equivalent to plasma levels of $16-32 \mathrm{mg} / \mathrm{l}(69-138$ $\mu \mathrm{mol} / \mathrm{l})$ and $10-20 \mathrm{mg} / 1(40-80 \mu \mathrm{mol} / \mathrm{l})$ respectively. For the placebo group saliva assays were carried out to exclude packaging error and mock adjustments of dosage were made. Other aspects of management were identical in each group. Neither the parents nor the family doctor knew which drug the child was taking.

Changes in the children's behaviour were assessed by means of a standard questionnaire completed by each mother. The questionnaire (see appendix) required estimates of the duration of sleep by night and by day, and enquired about 32 other items of behaviour, 16 applicable to all the children, and 16 only to those in the older groups; for these items, answers were given on an analogue scale $10 \mathrm{~cm}$ in length.

A specimen question and answer was included, and after a brief initial explanation each mother completed the questionnaire unaided, illiterate mothers being excluded. One question incorporated 
the Geordie word 'wingey,' which describes a child who is plaintive, uncooperative, and demanding.

At the beginning of the study (weeks 0-9) each mother filled in the same copy of the questionnaire on 3 occasions - the first time was during her child's stay in hospital when she was asked about his behaviour before his illness, and then at the clinic 3 weeks and 9 weeks after starting treatment. She used a different coloured pencil on each occasion so that by reference to her previous mark on the analogue scale she could record a change in either direction. If she had not noticed a change she put her later mark beside the previous one. In the analysis movements on the analogue scale of less than $5 \mathrm{~mm}$ in length were ignored because they indicated either a very small change or none. An example of a series of 3 answers is given below.

How easy is it to get him settled at night?

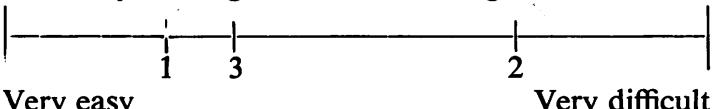

Very easy

Very difficult

At the end of the year's drug treatment (weeks 52-55) each mother was given a fresh copy of the same questionnaire to answer on 2 more occasions: while the child was still taking the drug and 3 weeks after stopping it.

\section{Results}

Weeks 0-9. At the beginning of the study the questionnaire was completed by mothers of 161 children, 56 of whom were starting phenobarbitone, 55 phenytoin, and 50 placebo. The children in each group were well matched with regard to age, gender, and whether their mothers stayed in hospital with them (Table 1). Five patients were withdrawn because their parents objected to the behavioural disturbances that they attributed to the drug: one of these children was receiving phenobarbitone, 2 were receiving phenytoin, and 2 placebo.

\section{Sleep}

Children in all 3 groups slept less both by night and day in the 3 weeks after the convulsion, the mean estimates of the reduction at night being 54 minutes for phenobarbitone, 42 minutes for

Table 1 Age and gender of children and number of mothers who stayed in hospital with them

\begin{tabular}{llll}
\hline Weeks $0-9$ & $\begin{array}{l}\text { Phenobarbitone } \\
(n=56)\end{array}$ & $\begin{array}{l}\text { Phenytoin } \\
(n=55)\end{array}$ & $\begin{array}{l}\text { Placebo } \\
(n=50)\end{array}$ \\
\hline Number < 14 months & 20 & 21 & 18 \\
Number of boys & 30 & 28 & 27 \\
Number whose mothers & 28 & 30 & 22 \\
$\quad$ stayed in hospital & & & \\
\hline
\end{tabular}

phenytoin, and 42 minutes for placebo, and during the day 4 minutes, 7 minutes, and 2 minutes respectively. At 9 weeks, night-time sleep continued to be shorter by about the same amount, but day-time sleep had decreased by about a further 10 minutes in all groups.

\section{Behaviour}

In order to ascertain which of the items of behaviour assessed by analogue scale reflected the same basic factors in behaviour, correlations were sought in the changes recorded on each occasion, and those items which were significantly correlated with each other with respect to all changes were grouped together in clusters (Table 2).

The largest cluster was centred around the characteristic of 'wingeness', with which 14 other items were directly or indirectly linked: a child who became more wingey was also likely to be harder to settle at night, to cry more, to be harder to cheer, to be more frightened of noises, to be worse tempered, to have more tantrums, to object more to being left, to be more active, to demand more attention, to be fussier about food, to be unsteadier, to fidget more, to be less obedient, and to want his own way more. There were 4 smaller clusters of 2 or 3 items each,

Table 2 Weeks 0-9-behavioural items showing those betwe'n which there was a significant correlation in changes at both 3 and 9 weeks

\begin{tabular}{rlrl}
\hline$N o^{*}$ & Index item & $N^{*}$ & Correlated items \\
\hline 16 & Wingeness & 7 & Crying a lot \\
& & 10 & Bad temper \\
& & $13^{+}$ & Tantrums \\
& & 14 & Dislike of being left \\
& & $20^{+}$ & Demanding attention \\
7 & Crying a lot & 24 & Unsteadiness \\
10 & Bad temper & 33 & Wanting own way \\
& & 3 & Not settling at night \\
13 & Tantrums & 8 & Difficulty in cheering \\
14 & Dislike of being left & 17 & Increased activity \\
24 & Unsteadiness & $31^{+}$ & Disobedience \\
& & 93 & Fear of noises \\
6 & Desire for cuddling & 27 & Fussiness about food \\
& & 8 & Difgetiness \\
5 & Difficulty feeding & 4 & Waking at night \\
& & $23^{+}$ & Fussiness about food \\
19 & Noisiness & $32^{+}$ & Poor appetite \\
18 & Thumb sucking & $17^{+}$ & Increased activity \\
12 & Shyness & 28 & Difficulty in dressing \\
15 & Fears & 11 & Liking for bath \\
21 & Upset by knocks & & None \\
22 & Difficulty potting & & None \\
25 & Dropping things & & None \\
26 & Breaking things & & None \\
29 & Not sharing & & None \\
30 & Hitting others & & None \\
34 & Poor speech & & None \\
& & None \\
\hline
\end{tabular}

*See appendix for details.

The index item for each cluster of correlated items is in italics.

For all correlations $P=<0.05$; for items marked $+P=<0.0001$. 
centred around ease of feeding, desire for cuddling, noisiness, and thumb-sucking, some items being common to more than one cluster. Nine items showed no significant correlations, so that with the 5 clusters there were $\mathbf{1 4}$ factors that changed independently.

In these 14 factors the proportion of mothers recording changes from their initial answers in one direction compared with the other was very similar for all groups at both 3 and 9 weeks (Figure). The only significant difference $(P=<0.05>0.01)$ between drug groups was at 9 weeks when fewer children taking phenytoin were reported as being shyer with strangers or as having fears about things, than those taking placebo.

Excluding these two factors the answers of mothers in all groups were considered together and binomial tests were applied to assess the significance of the proportion recording changes in one direction compared with the other. At 3 weeks a significant proportion of mothers in all groups was reporting deteriorations in the 'wingeness' cluster of items in particular, in the 'cuddles' and 'activity' clusters, and in a tendency to hit other children more and share with them less.

If the extent of such changes is assessed by the mean movements on the analogue scale, then

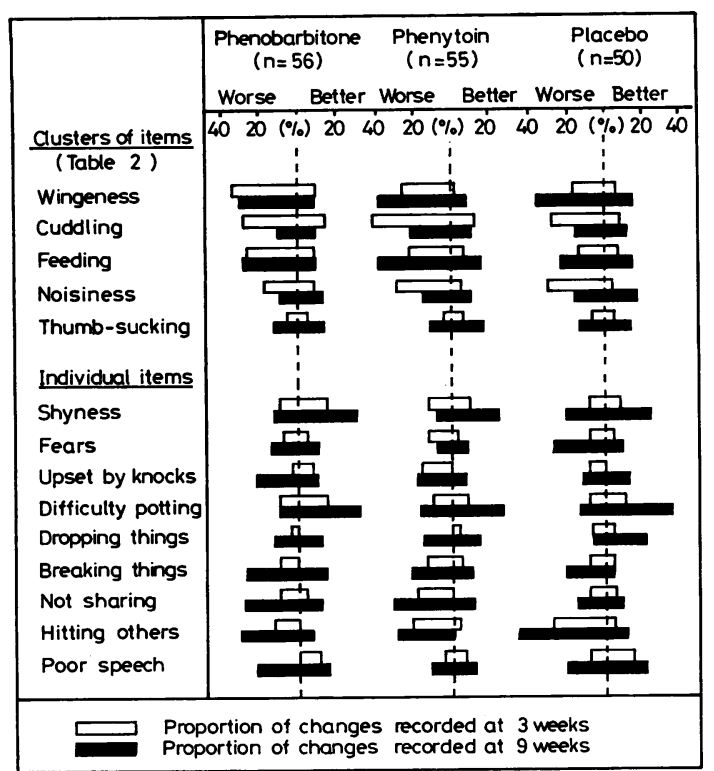

The proportion is the same as for index item (Table 2). Movements $<5 \mathrm{~mm}$ on the analogue scale are not included.

Figure Proportion of children for whom a change in behaviour was recorded 3 weeks and 9 weeks after starting treatment. mothers regarded the deterioration in settling and sleeping at night, and in having tantrums and hitting other children, as being particularly severe. At 9 weeks a significant proportion of mothers was still recording most of these changes, though there was a partial improvement in several items that had initially deteriorated. At 9 weeks a significant proportion of mothers recorded changes in two other items: a greater inclination to sit on the potty, and to break things on purpose.

In the factors applicable to all children there were no significant differences between the two age groups. If children whose mothers stayed in hospital with them are compared with those whose mothers did not, significant differences $(P=<0.05>0.01)$ emerge for two items: at 3 weeks more of the former were inclined to break things, and at 9 weeks more were easier to cheer.

Weeks 52-55. At the end of the year's treatment the questionnaire was completed by mothers of 62 children, of whom 26 had been taking phenobarbitone, 19 phenytoin, and 17 placebo. The questions about the duration of sleep were not properly answered by many mothers and inadequate data are available for analysis. In most of the behavioural items about equal numbers of mothers recorded changes in either direction. If the changes in each drug group are compared, 4 significant differences emerge among children taking phenobarbitone: $23 \%$ were recorded as becoming less wingey, $15 \%$ as less fidgety, $19 \%$ as more shy, and $36 \%$ as having a smaller appetite, compared with children stopping phenytoin and placebo for whom the percentages were $6 \%, 0 \%, 0 \%$, and $11 \%$ respectively.

The mean distance of the move along the analogue scale recorded for these items in the phenobarbitone group was not large. None of the children in whom these changes were recorded had an obvious preexisting behavioural or neurological disturbance and no other predictive feature was apparent.

\section{Discussion}

This study was not double-blind, but bias was unlikely because no mother knew the identity of the drug and each completed the questionnaire without help and away from the investigator. Thus, any drug-associated behavioural effects should emerge as differences between the placebo group and those taking active drugs.

Many more changes in behaviour were recorded between weeks $0-9$ than between weeks 52-55. The frequency and character of these changes were similar for all groups, which suggests that they were due to factors other than drugs. It has been 
suggested that behavioural disturbance might arise from the febrile convulsion itself or in response to parental concern about the seizure and its treatment. ${ }^{7}$ We consider however, that the most likely explanation for the initial disturbance was the child's admission to hospital, which is well known ${ }^{10-12}$ to have a temporary upsetting effect on behaviour in this age group.

The changes in our children are very similar to those described after a stay in hospital, and for several items exhibited the recognised pattern of initial deterioration followed by improvement. It is interesting that even a short stay in hospital after a febrile convulsion should have such a pronounced effect on behaviour, often still detectable 9 weeks later. We did not find large differences between those children whose mothers stayed in hospital with them and those whose mothers did not. The disorders attributed to phenobarbitone are very similar to those resulting from admission to hospital, but this does not seem to have been taken into account in earlier studies.

Some of the changes we recorded at 9 weeks probably reflected the normal development of the child during this period, including for example, progressive decline in the duration of day-time sleeping, greater willingness to sit on the potty, and an increased tendency to break things on purpose.

It is possible that any behavioural disturbance resulting from initiation of treatment was submerged in the greater effect of a stay in hospital; its identification would require a study of children starting treatment without admission to hospital. At the end of our study, when drug effects would be expected to be unalloyed by extraneous factors, changes in behaviour were noted in significantly more children (about $20 \%$ ) who had been taking phenobarbitone, the proportion being similar to that found by Camfield et al. ${ }^{7}$ The reduction in wingeness and fidgetiness, and the increase in shyness, are consistent with the view that phenobarbitone may increase activity and awkwardness, and the reduction in appetite could result from diminished activity.

However the magnitude of these changes was not large. It is possible that we avoided more frequent and severe behavioural effects from phenobarbitone by keeping salivary levels below $16 \mathrm{mg} / 1$, although previous reports have suggested that such effects are not dose-related.

\section{Conclusions}

We conclude that phenobarbitone in dosages producing salivary concentrations of $8-16 \mathrm{mg} / 1$ does not appreciably disturb the behaviour of most children under 3 , and that if it does, the disturbance is not generally severe. Phenytoin in dosages producing salivary concentrations of $1 \cdot 0-2 \cdot 0 \mathrm{mg} / 1$ does not cause any appreciable behavioural disturbance. We suggest that, in this age group, a drug started concurrently may sometimes be blamed for the behavioural disturbance caused by a stay in hospital; this possibility should be explained to parents and should be taken into account before the drug is stopped.

\section{Appendix}

\section{Questionnaire items}

(1) On average how long does he sleep each night?

(2) On average how long does he sleep each day?

Questions 3-34 were answered on an analogue scale $10 \mathrm{~cm}$ in length

(3) How easy is it to get him to settle at night ? Very easy-very difficult

r(4) How often does he wake up in the night? Very often-very seldom

(5) How easy is it to get him to take his feed? Very easy-very difficult

(6) How often does he want to be picked up and cuddled? Constantly -very seldom

(7) How much does he cry? Very often-very seldom

(8) How easy is it to cheer him up when he's angry or unhappy? Very easy-very difficult

(9) Is be frightened by unexpected noises? Very much-not at all

(10) Is he pleasant or bad-tempered? Very pleasant-very badtempered

(11) What does he think of having a bath? Loves it-hates it

(12) How is he with strangers? Very shy-very friendly

(13) How often does he have tantrums? Very often-never

(14) Does he mind if you leave him alone for a few moments? Very much-not at all

(15) Does he seem to have fears about things? Very much-not at all

(16) Is he often wingey? Very often-never

(17) How active is he? Very active-not at all active

(18) How much does he suck his thumb or his dummy? Constantlynever.

Questions 19-34 were answered only by mothers of children $>13$ months old

(19) How noisy is he? Very noisy-very quiet

(20) Does he demand a lot of attention? Very much so-very little

(21) How much is he upset by knocks and bumps? Very muchvery little

(22) How easy is it to get him to sit on the potty? Very easy-very difficult

(23) How fussy is he about his food ? Very fussy-not at all fussy

(24) How steady is he on his feet? Very steady-very unsteady

(25) Does he drop things by mistake? Very often-almost never

(26) Does he break things on purpose ? Very often-never

(27) Does he fidget? A great deal-not at all

(28) How easy is it to get him dressed? Very easy-very difficult

(29) Does he allow other children to play with his toys? Very willingly -not at all

(30) How often does he hit other children? Never-very often

(31) How well does he do what he's told? Very well-very badly

(32) Has he a good appetite? Very good-very poor

(33) Does helike to have his own way? Very much so-not at all

(34) How clearly does he speak for his age? Very clearly-not at all clearly.

We thank Dr R F Garside and Dr C J Bulpitt for advice, and the many mothers who so painstakingly completed our questionnaire.

\section{References}

1 Thorn I. A controlled study of prophylactic long-term treatment of febrile convulsions with phenobarbital. Acta Neurol Scand [Suppl] 1975; Supplement 60, 67-73. 
2 Heckmatt J Z, Houston A B, Clow D J, et al. Failure of phenobarbitone to prevent febrile convulsions. $\mathrm{Br} \mathrm{Med} J$ 1976; i: 559-61.

3 Wolf S M, Forsythe A. Behavior disturbance, phenobarbital, and febrile seizures. Pediatrics 1978; 61: 728-31.

- Knudsen F U, Vestermark S. Prophylactic diazepam or phenobarbitone in febrile convulsions: a prospective, controlled study. Arch Dis Child 1978; 53: 660-3.

5 Bower B D. Epilepsy. In: Valman H B, ed. Paediatric therapeutics. Oxford: Blackwell Scientific, 1979: 45-59.

6 Stores G. Behavioural effects of anti-epileptic drugs. Modern Medicine 1979; 24 December, 49-50.

7 Camfield C S, Chaplin S, Doyle A B, Shapiro S H, Cummings C, Camfield P R. Side effects of phenobarbital in toddlers; behavioral and cognitive aspects. $J$ Pediatr 1979; 95: 361-5.

8 Association of British Pharmaceutical Industry. Data sheet compendium 1980/81. London: Datapharm Publications,'1980: 795-6.
- Bacon C J, Hierons A M, Mucklow J C, Webb J K G, Rawlins M D, Weightman D. Placebo-controlled study of phenobarbitone and phenytoin in the prophylaxis of febrile convulsions. Lancet 1981 ; ii : $600-4$.

10 Prugh D G, Staub E M, Sands H H, Kirschbaum R M, Lenihan $E$ A. A study of the emotional reactions of children and families to hospitalization and illness. Am J Orthopsychiatry 1953; 23: 70-106.

11 Vernon D T A, Schulman J L, Foley J M. Changes in children's behaviour after hospitalization. Am J Dis Child 1966; 111 : 581-93.

12 Brain D J, Maclay I. Controlled study of mothers and children in hospital. Br Med J 1968; i: 278-80.

Correspondence to Dr C J Bacon, Friarage Hospital, Northallerton, North Yorks DL6 1JG.

Received 2 October 1980 